\title{
Evaluation of the prognostic and predictive value of HER family mRNA expression in high-risk early breast cancer: A Hellenic Cooperative Oncology Group (HeCOG) study
}

\begin{abstract}
AK Koutras ${ }^{*, 1,16}$, KT Kalogeras ${ }^{2,3,16}$, M-A Dimopoulos ${ }^{4}$, RM Wirtz ${ }^{5}$, U Dafni ${ }^{6}$, E Briasoulis ${ }^{7}$, D Pectasides ${ }^{8}$, H Gogas', C Christodoulou' ${ }^{10}$, G Aravantinos '1, G Zografos ${ }^{12}$, E Timotheadou', P Papakostas ${ }^{13}$, H Linardou'4, E Razis $^{15}$, T Economopoulos ${ }^{8}$, HP Kalofonos' and G Fountzilas ${ }^{2}$

'Division of Oncology, Department of Medicine, University Hospital of Patras, Rion, Greece; ${ }^{2}$ Department of Medical Oncology, Papageorgiou Hospital, Aristotle University of Thessaloniki School of Medicine, Thessaloniki, Greece; ${ }^{3}$ Hellenic Cooperative Oncology Group, Data Office, Athens, Greece; ${ }^{4}$ Department of Clinical Therapeutics, Alexandra Hospital, University of Athens School of Medicine, Athens, Greece; ${ }^{5}$ Siemens Healthcare Diagnostics, Cologne, Germany; ' Laboratory of Biostatistics, University of Athens School of Nursing, Athens, Greece; 'Department of Medical Oncology, loannina University Hospital, loannina, Greece; ${ }^{8}$ Second Department of Internal Medicine, 'Attikon' University Hospital, Athens, Greece; ${ }^{9}$ Laiko General Hospital, University of Athens School of Medicine, Athens, Greece; ${ }^{10}$ Second Department of Medical Oncology, Metropolitan Hospital, Piraeus, Greece; ${ }^{\prime}$ Third Department of Medical Oncology, Agii Anargiri Cancer Hospital, Athens, Greece; ${ }^{12}$ Department of Surgery, University of Athens School of Medicine, Athens, Greece; ${ }^{13}$ Oncology Department, Hippokration Hospital, Athens, Greece; ${ }^{14}$ First Department of Medical Oncology, Metropolitan Hospital, Piraeus, Greece; ${ }^{15}$ First Department of Medical Oncology, Hygeia Hospital, Athens, Greece
\end{abstract}

The aim of the study was to evaluate the prognostic ability of the transcriptional profiling of the HER family genes in early breast cancer, as well as to investigate the predictive value of HER2 mRNA expression for adjuvant treatment with paclitaxel. RNA was extracted from 268 formalin-fixed paraffin-embedded (FFPE) tumour tissue samples of high-risk breast cancer patients enrolled in the randomised HE I0/97 trial, evaluating the effect of dose-dense anthracycline-based sequential adjuvant chemotherapy with or without paclitaxel. The mRNA expression of all four HER family members was assessed by kinetic reverse transcription-polymerase chain reaction (KRT-PCR). The overall concordance between KRT-PCR and IHC/FISH for HER2 status determination was 74\%. At a median follow-up of 8 years, multivariate analysis showed that EGFR and HER2 mRNA expression was associated with reduced overall survival (OS). HER3 and HER4 mRNA level had a favourable prognostic value in terms of OS and disease-free survival (DFS), respectively. Adjusting for HER2 mRNA expression, OS and DFS did not differ between treatment groups. These data indicate that EGFR as well as HER2 are prognostic factors of worse clinical outcomes, whereas HER3 and HER4 gene transcription is associated with better prognosis in high-risk early breast cancer. However, HER2 mRNA expression did not predict clinical benefit from paclitaxel. Kinetic RT-PCR represents an alternative method for evaluating the expression of HER family members in FFPE breast carcinomas.

British Journal of Cancer (2008) 99, I775- 1785. doi:I0.1038/sj.bjc.6604769 www.bjcancer.com

Published online 4 November 2008

(c) 2008 Cancer Research UK

Keywords: HER family; mRNA; KRT-PCR; prognostic value; predictive value; breast cancer

Adjuvant chemotherapy improves disease-free survival (DFS) and overall survival (OS) in early-stage breast cancer (EBCTCG, 2005) with taxanes representing active agents in such a treatment. However, chemotherapy is associated with potentially life-threatening side effects. Therefore, the identification of reliable prognostic factors as well as biological markers that might have the ability to predict therapeutic response is crucial. So far, no biomarkers have been identified that can reliably predict clinical benefit from paclitaxel in breast cancer patients.

* Correspondence: Dr AK Koutras, Division of Oncology, Department of Medicine, University Hospital of Patras, Patras Medical School, Rion 26504, Greece; E-mail: angkoutr@otenet.gr

${ }^{16}$ These two authors have contributed equally to this work

Received I August 2008; revised 7 October 2008; accepted II October 2008; published online 4 November 2008
The human epidermal growth factor receptor (HER) family comprises of four homologous members: ErbB-1 (epidermal growth factor receptor (EGFR) or HER1), ErbB-2 (HER2) for which no ligand has been described so far, ErbB-3 (HER3) which is characterised by its impaired kinase activity, and ErbB-4 (HER4) (Mosesson and Yarden, 2004). There is an extensive literature on the role of the HER family in breast cancer and particularly that of HER2, which is considered to be a key oncogene in breast carcinogenesis. Overexpression or amplification of HER 2 occurs in $15-30 \%$ of breast carcinomas and is considered to confer a more aggressive biology and an unfavourable impact on the course of the disease (Slamon et al, 1987). Moreover, it has been suggested that HER2 overexpression or amplification in breast cancer predicts greater sensitivity to anthracycline-containing chemotherapy (Gennari et al, 2008) and resistance to the CMF regimen (Gusterson et al, 1992). HER2 may also identify patients who are likely to benefit from higher doses of adjuvant chemotherapy 
(Dressler et al, 2005). The predictive value of HER2 expression regarding the response to taxane-based chemotherapy is considered controversial and the results of the studies have been conflicting, so far (Pritchard et al, 2008). Although some trials have supported an interaction between HER2 overexpression and taxane activity (Konecny et al, 2004; Hayes et al, 2007), others have failed to demonstrate such an association (Gonzalez-Angulo et al, 2004). Only a limited number of studies have evaluated the effect of taxane-containing regimens with respect to HER2 status in the adjuvant setting (Martin et al, 2005; Kostopoulos et al, 2006; Hayes et al, 2007).

In the light of clinical data suggesting that HER2 can be useful as a predictive marker for both trastuzumab and chemotherapy, standardised determination of the HER2 status in tumours has become more important. HER2 can be analysed at the DNA, the mRNA or the protein level. Various techniques are available, each with advantages and disadvantages. For practical reasons, immunohistochemistry (IHC) using an anti-HER2 antibody is currently the method of choice for HER2 testing. However, major drawbacks of IHC are that the results are not quantitative, the interpretation is significantly influenced by several technical factors and the inter-observer variation is quite large. Although these discrepancies are improved by the use of standardised IHC tests (such as the HercepTest), it is generally recommended that $(2+)$ HER2 immunostaining needs to be further validated by fluorescence in situ hybridisation (FISH) analysis (Ellis et al, 2000; Mass et al, 2000; Birner et al, 2001; Bartlett et al, 2003). Despite efforts to standardise these assays, substantial intra- and interlaboratory variability of the results still exist. Kinetic reverse transcription-polymerase chain reaction (kRT-PCR) has recently been suggested as an alternative technique for the detection and quantification of HER2 expression. kRT - PCR is simple, relatively fast and produces reliable, quantitative and reproducible results. Moreover, it can easily be standardised, reduces inter-observer variability and does not require experienced pathologists for interpretation. However, a disadvantage of this technique is the specific requirements for handling of the tissue specimens to preserve the integrity of RNA. Recent studies have shown that the small amounts of degraded RNA in archival formalin-fixed paraffin-embedded (FFPE) tissues can be successfully amplified and detected using kRT - PCR techniques (Gjerdrum et al, 2004).

EGFR is overexpressed in several human tumours and is considered to initiate a variety of important steps during the malignant transformation. It has been estimated that $45 \%$ of human breast carcinomas overexpress EGFR (range, 14-91\%) (Klijn et al, 1992). So far, there are no widely accepted criteria for the determination of EGFR status. EGFR overexpression has been associated with oestrogen receptor (ER) and progesterone receptor (PR) negativity (Pawlowski et al, 2000; Ferrero et al, 2001; Tsutsui et al, 2002; Bieche et al, 2003). Moreover, there may be an association between EGFR positivity and high histological grade or lymph node involvement, although not all existing studies are in agreement (Pawlowski et al, 2000; Ferrero et al, 2001; Witton et al, 2003; Rampaul et al, 2004; Tzaida et al, 2007). Currently, the prognostic significance of EGFR in breast cancer patients remains unclear. In addition, HER3 overexpression has been documented in $20-30 \%$ of invasive breast carcinomas. The prognostic significance of HER3 expression is also poorly documented and the available data are conflicting (Quinn et al, 1994; Travis et al, 1996; Pawlowski et al, 2000). With respect to the HER4 receptor, the current evidence suggests that it is characterised by antiproliferative activity (Naresh et al, 2006). HER4 overexpression has been reported as a favourable prognostic factor in the literature (Pawlowski et al, 2000; Suo et al, 2002; Witton et al, 2003). The HER family represents therefore an attractive area for the application of targeted therapies in breast cancer and significant treatment advances have been made, so far. As transsignalling is now considered an essential feature of HER family function, the role of lateral signalling partners is also becoming increasingly important.

In this study, we assessed the prognostic significance of HER family mRNA expression using kRT-PCR, in a series of high-risk early breast cancer patients, treated with dose-dense anthracycline-based sequential adjuvant chemotherapy with or without paclitaxel, within the context of a randomised phase III clinical trial. Furthermore, we investigated whether HER family mRNA expression in the tumour could possibly identify patients who are likely to benefit from the addition of paclitaxel to adjuvant chemotherapy.

\section{MATERIALS AND METHODS}

\section{Patients}

Formalin-fixed paraffin-embedded tissue blocks of primary breast cancer were retrospectively collected from 268 patients who were part of the Hellenic Cooperative Oncology Group (HeCOG) 10/97 trial population. The basic patient and tumour characteristics are shown in Table 1. The HE10/97 trial randomised a total of 595 high-risk (T1-3N1M0 or T3N0M0) breast cancer patients in the period 1997-2000, to receive either 4 cycles of epirubicin (E) followed by 4 cycles of intensified CMF (cyclophosphamide, methotrexate and 5-fluorouracil) combination chemotherapy (E-CMF) or 3 cycles of epirubicin followed by 3 cycles of paclitaxel (T) and 3 cycles of intensified CMF (E-T-CMF). Chemotherapy cycles were administered every 2 weeks and patients received granulocyte-colony stimulating factor (G-CSF) support. The trial was approved from the Bioethics Committee of the Aristotle University of Thessaloniki and patients provided written informed consent prior to enrolment. All participating patients also gave written informed consent for research use of their biologic material. The results of the HE10/97 study have been recently reported (Fountzilas et al, 2005).

\section{Pathologic determinations}

Primary tumour diameter and axillary nodal status were obtained from the histopathological report. ER and PR status was assessed by IHC, whereas relative information was provided by the participating institutions according to their own reference laboratories. Tissue paraffin sections stained for ER/PR were considered as positive even when only a small number of neoplastic cells displayed nuclear immunoreactivity. Histological grade was evaluated according to the Scarff, Bloom and Richardson system.

\section{Molecular and immunohistochemical studies}

Owing to the logistical and organisational barriers arising from the retrospective nature of the study, collection of FFPE tumour tissue samples was possible in less than half of the patients enrolled in the HE10/97 prospective clinical trial. RNA was isolated from 268 FFPE tumour tissue samples employing an experimental method based on proprietary magnetic beads from Siemens Healthcare Diagnostics (Cologne, Germany). For all tumour samples included in the analysis the number of malignant cells represented at least $75 \%$ of all nucleated cells per section, as verified by haematoxylineosin staining. Kinetic RT - PCR was applied for the assessment of the expression of the EGFR, HER2, HER3, and HER4 genes using gene-specific TaqMan ${ }^{\text {TM }}$-based primer/probe sets. Forty cycles of nucleic acid amplification were applied and the cycle threshold $\left(C_{\mathrm{t}}\right)$ values of the target genes were identified. $C_{\mathrm{t}}$ values were normalised by subtracting the $C_{\mathrm{t}}$ value of the housekeeping gene RPL37A from the $C_{\mathrm{t}}$ value of the target gene $\left(\Delta C_{\mathrm{t}}\right)$. RNA results were then reported as $40-\Delta C_{\mathrm{t}}$ values, which would correlate proportionally to the mRNA expression level of the target gene. 
Table I Basic patient and tumour characteristics

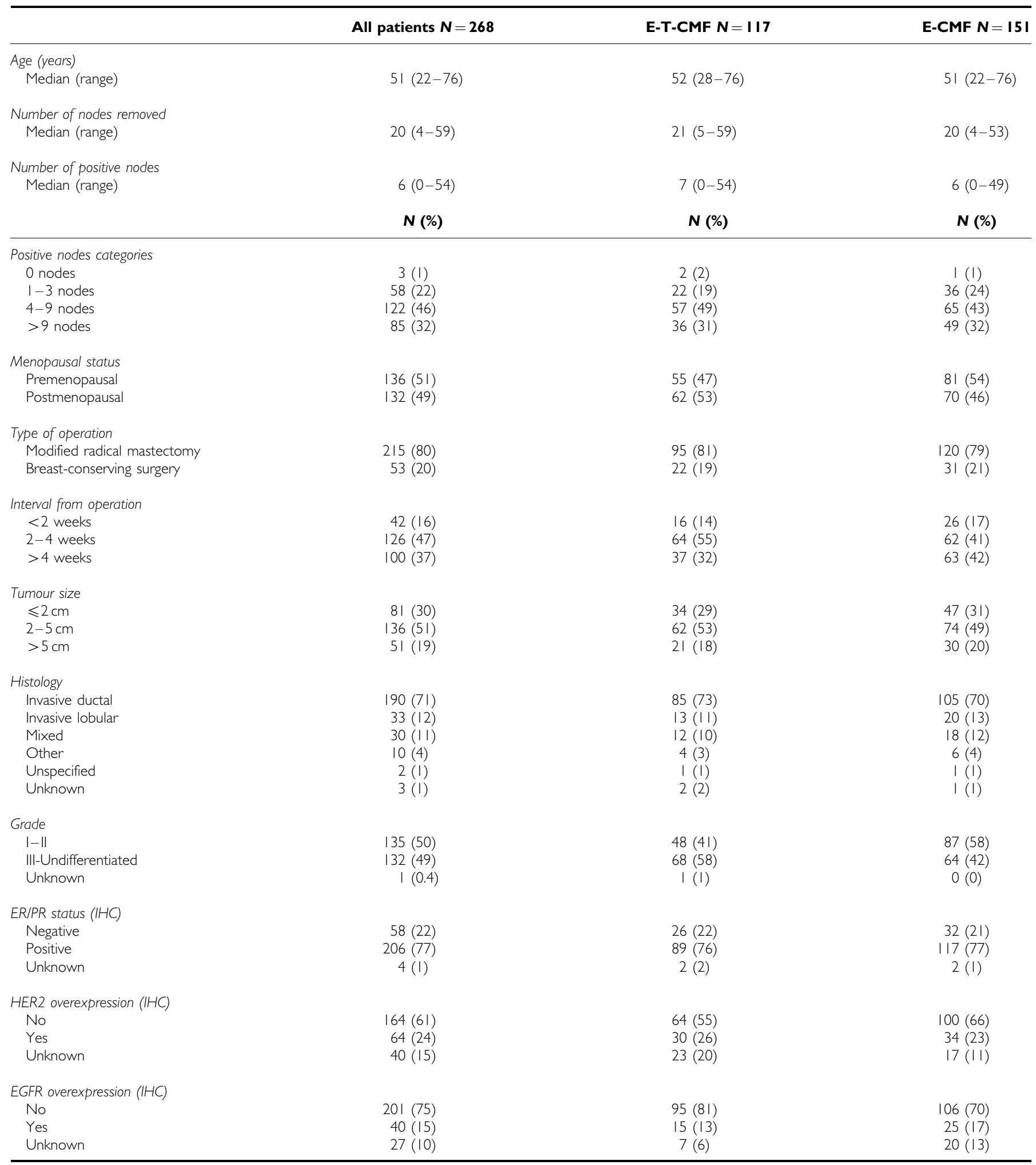

Patient characteristics are well balanced between the two arms, with the exception of grade $(P=0.010)$, a difference also observed in the prospective clinical trial.

In short, each FFPE slide (5 $\mu \mathrm{m}$ thick) was deparaffinised in xylol and ethanol, the pellet was washed with ethanol and dried at $55^{\circ} \mathrm{C}$ for $10 \mathrm{~min}$. The pellet was then lysed and proteinised overnight at $55^{\circ} \mathrm{C}$ with shaking. After addition of a binding buffer and the magnetic particles (Siemens Healthcare Diagnostics, Cologne, Germany) nucleic acids were allowed to bind to the particles for $15 \mathrm{~min}$ at room temperature. On a magnetic stand, the supernatant was aspirated and the beads were washed several times with a washing buffer. After addition of an elution buffer and incubation for $10 \mathrm{~min}$ at $70^{\circ} \mathrm{C}$, the supernatant was aspirated on a magnetic stand without touching the beads. After normal DNAse I treatment for $30 \mathrm{~min}$ at $37^{\circ} \mathrm{C}$ and inactivation of DNAse I the RNA 
quality and quantity was checked by measuring absorbance at 260 and $280 \mathrm{~nm}$. RNA was then used in RT-PCR. The primer/ probe sets used for amplification of the target genes were the following:

EGFR Probe CCTTGCCGCAAAGTGTGTAACGGAAT

Forward Primer CGCAAGTGTAAGAAGTGCGAA

Reverse Primer CGTAGCATTTATGGAGAGTGAGTCT

HER2 Probe ACCAGGACCCACCAGAGCGGG

Forward Primer CCAGCCTTCGACAACCTCTATT

Reverse Primer TGCCGTAGGTGTCCCTTTG

HER3 Probe CTCAAAGGTACTCCCTCCTCCCGGG

Forward Primer CGGTTATGTCATGCCAGATACAC

Reverse Primer GAACTGAGACCCACTGAAGAAAGG

HER4 Probe CACAGACTGCTTTGCCTGCATGAATTTC

Forward Primer GAGGCTGCTCAGGACCTAAGG

Reverse Primer GAGTAACACATGCTCCACTGTCATT

Human reference total RNA pooled from 10 human cell lines (Stratagene, La Jolla, California, USA) was used as a positive control. RNA-free DNA extracted from tumour tissues was used as a negative control.

Data regarding EGFR and HER2 protein expression using IHC were available in 241 and 228 patients, respectively (Table 1). EGFR was assessed at the Department of Pathology of the Metaxas Cancer Hospital, Athens, as described earlier (Tzaida et al, 2007). HER2 was determined at the Department of Pathology of the Hygeia Hospital, Athens, with additional analysis of cases with an IHC score of $2+$ by FISH, as described earlier (Kostopoulos et al, 2006).

\section{Statistical analysis}

Categorical data are presented as counts and corresponding percentages, whereas continuous data are presented as medians and ranges. For all receptors, the median was the pre-specified cutoff point and its distinguishing ability for patient prognosis was tested by means of the log-rank test. In case of no distinguishing ability of the median in terms of OS, the plan was to proceed with an exploratory analysis to test if the 25th and 75th percentiles were more appropriate cutoffs. Exploratory analysis was performed in a subgroup of the sample and validated in the rest of the patients. If the 25th and 75th percentiles were not validated as appropriate cutoff points, exploration would continue from the 10 th to the 90th percentiles. In case a conclusion was reached on a cutoff point through exploration, subsequent analysis would initially be performed excluding the corresponding gene and repeated including it at the optimal cutoff (ability to distinguish OS significantly in the whole sample). We present the results of the analysis including this gene, only in cases where the results were not altered significantly. Comparison of categorical data between groups of patients was performed using the $\chi^{2}$-test. Variables included in the comparisons were involved lymph nodes $(0-3 v s \geqslant 4)$, histological grade (good or moderate $v s$ poor or undifferentiated), ER and PR status (positive $v s$ negative), tumour size $(\leqslant 2$ vs 2-5 vs $>5 \mathrm{~cm}$ ), histology (ductal vs lobular vs other) and age $(<50$ vs $>50$ years). Continuous data were compared using the Mann-Whitney test, or the Kruskal-Wallis test in case of more than two groups. Correlations among the receptors were assessed using the Spearman's Correlation Coefficient Method.

Overall survival was measured from time of chemotherapy initiation to patient's last contact or death. Disease-free survival was measured from time of chemotherapy initiation to patient's last contact or disease progression. Cases of disease progression, deaths from any cause without verified relapse and second cancers were treated as events in the estimation of DFS (Hudis et al, 2007). Survival was estimated using the Kaplan-Meier method. Comparisons between groups of patients, as defined by receptor cutoffs, were performed using the log-rank test. Multivariate Cox analysis including age ( $<50 v s>50$ years), involved lymph nodes $(0-3 v s$ $\geqslant 4$ ), histology (ductal vs lobular vs other), histological grade (good or moderate $v s$ poor or undifferentiated), size ( $\leqslant 2 v s 2-5 v s$ $>5 \mathrm{~cm}$ ), ER/PR status (positive $v s$ negative), hormonotherapy (yes $v s$ no), radiotherapy (yes $v s$ no), EGFR ( $\geqslant 75$ th percentile $v s<75$ th percentile), and HER2, HER3, HER4 ( $\geqslant$ median $v s<$ median) was performed. Variable selection was performed based on the likelihood ratio test with an exclusion criterion set at 0.10 . The final model was adjusted for the group of randomisation (E-T-CMF vs E-CMF). Interaction between paclitaxel containing chemotherapy and the genes of interest was also considered. Level of significance was $\alpha=0.05$ for all tests. Results of this study were presented according to reporting recommendations for tumour marker prognostic studies (McShane et al, 2005). The statistical analysis was conducted using SPSS 11 for Windows.

\section{RESULTS}

\section{Normalised mRNA expression of HER family receptors}

The distribution of tumour samples according to the normalised expression of mRNA encoding for HER family receptors is shown in Figure 1. The median value for EGFR was 32.95 (range, 24.8536.11), for HER2 35.56 (range, 30.32-40.98), for HER3 34.63 (range, 28.3-37.1), and for HER4 31.79 (range, 24.67-35.43).

\section{Concordance between kinetic RT - PCR and IHC}

The total number of tumours with data available from both IHC and kRT-PCR was 240 and 228 for EGFR and HER2, respectively. For EGFR, 39 of the 240 tumours (16\%) were IHC positive, whereas 59 tumours $(24.5 \%)$ were kRT - PCR positive. For HER2, 64 of the 228 tumours $(28 \%)$ were IHC/FISH positive, whereas 113 tumours (49.5\%) had HER2 mRNA expression above the median, as assessed by kRT - PCR. For these tumours, we found a statistically significant association between the evaluations obtained by the two methods, for the EGFR (Mann-Whitney test, $P<0.001$ ) and the HER2 (Kruskal-Wallis test, $P<0.001$ ) receptors. The observed overall concordance between the determination of HER2 by kRT PCR and IHC/FISH was $74 \%$. The levels for sensitivity and specificity were 92 and $67 \%$, respectively. The overall agreement between kRT-PCR and IHC for EGFR was 75\%. Sensitivity and specificity were 49 and $80 \%$, respectively (Table 2 ).

\section{Relationships among HER family receptors mRNA expression}

A positive correlation was found between HER2 and HER 3 mRNA levels $(r=0.224, P<0.001)$. No association was demonstrated between HER2 and the other two family members. Moreover, HER3 and HER4 mRNA values were positively correlated to each other $(r=0.444, P<0.001)$ and negatively correlated to EGFR $(r=-0.143, P=0.019$ and $r=-0.125, P=0.043$, respectively).

\section{Association of HER family receptors mRNA expression with clinicopathological parameters}

EGFR mRNA expression was inversely related to the presence of ER $(P=0.044)$. HER2 was positively associated with the number of involved lymph nodes $(P=0.013)$. HER3 mRNA expression was associated with ER positivity $(P=0.017)$, whereas HER4 was associated with histopathological grade I + II $(P=0.001)$ and ER and PR positivity $(P<0.001$ and $P<0.001$, respectively). Furthermore, EGFR mRNA expression was inversely associated with ductal histology $(P=0.029)$, whereas that of HER2 was positively associated with ductal histological type $(P=0.001)$. 

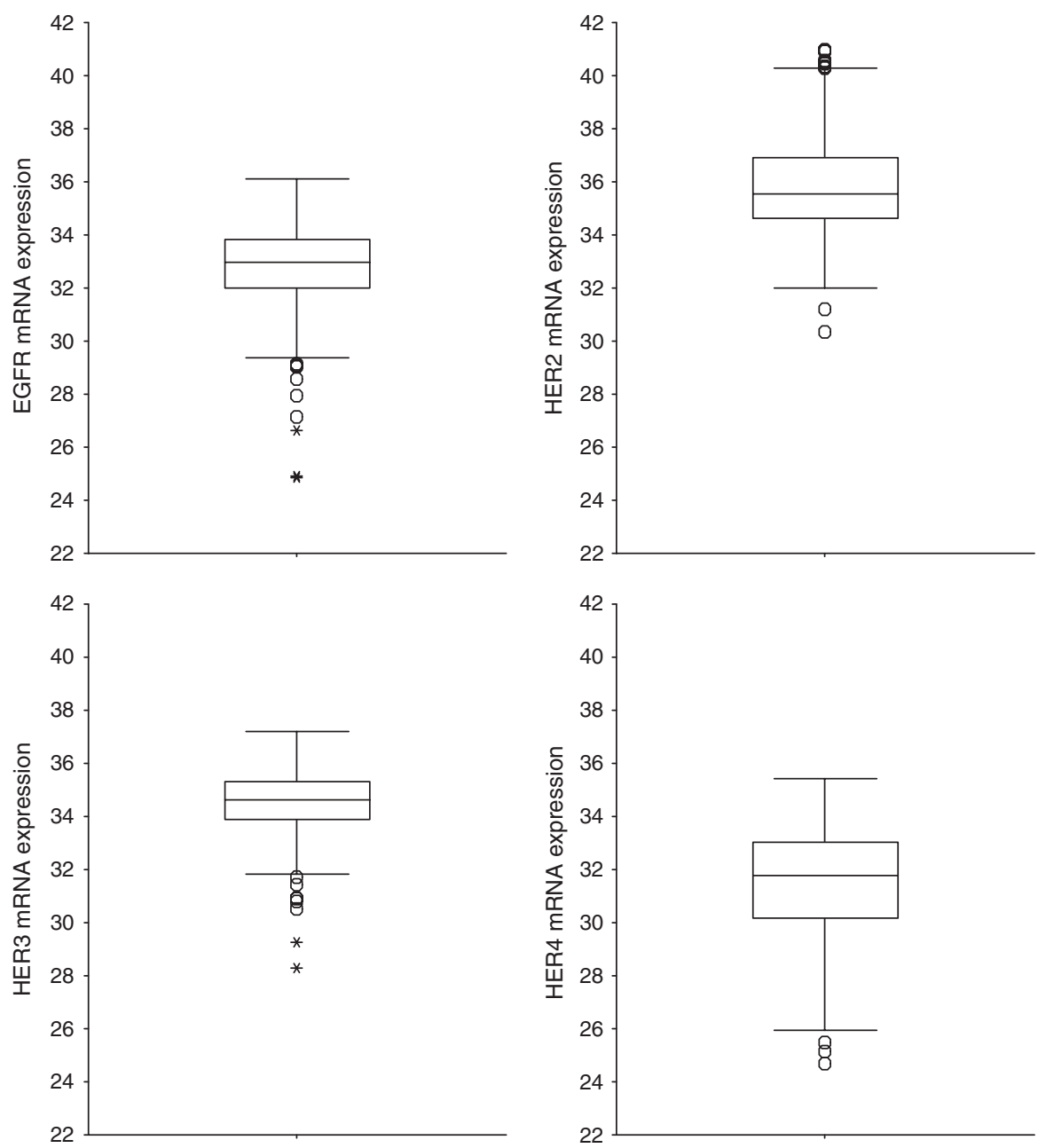

Figure I Distribution of breast carcinoma specimens according to normalised expression of mRNA encoding for HER family receptors.

Table 2 Evaluation of HER2 and EGFR by kRT-PCR compared with IHC

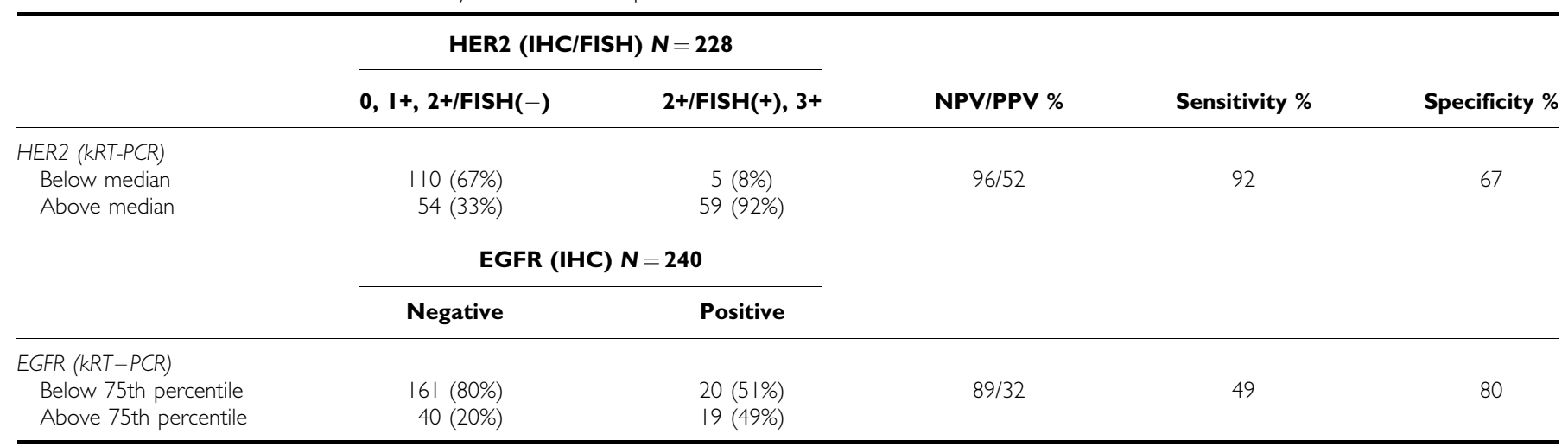

NPV, negative predictive value; PPV, positive predictive value.

Prognostic value of HER family receptors mRNA expression

Survival status of the patients was updated in October 2007. The median follow-up time was 95.5 months (95\% CI: 92.4-98.6, range, 7-117 months). During this time, 87 patients had developed a relapse and 61 patients had died. The 3-year OS was 93\% (95\% CI:
90-96\%), whereas the 5-year OS was $85 \%$ (95\% CI: $81-90 \%)$. The 3 -year DFS was $80 \%$ (95\% CI: 75-84\%), whereas the 5-year DFS was $74 \%$ (95\% CI: $68-79 \%)$.

For each of the HER family receptors, three cutoff points (25th, 50th and 75th percentiles) were assessed for prognostic value. In the majority of cases, the median (50th percentile) was the optimal cutoff point. However, in the case of EGFR the 75th percentile was 
the best threshold, allowing us to distinguish two populations of significantly different prognosis. Using the 75th percentile, patients whose tumours had increased EGFR mRNA expression had significantly reduced OS (22 out of 67 deaths in EGFR-positive vs 38 out of 200 deaths in EGFR-negative patients, log-rank $P=0.022$ ) (Figure 2A1). The hazard ratio (HR) for death in EGFRpositive patients was 1.83 (95\% CI: $1.08-3.09, P=0.024)$. The median value was used as a cutoff point for HER2, HER3 and HER4. A significant association between HER2 mRNA overexpression and reduced OS was demonstrated (39 out of 134 deaths in HER2-positive vs 22 out of 134 deaths in HER2-negative patients, log-rank $P=0.024$ ) (Figure $2 \mathrm{~A} 2$ ). The $\mathrm{HR}$ for death in HER2-positive patients was 1.81 (95\% CI: $1.07-3.05, P=0.027)$. In contrast, HER3 as well as HER4 mRNA expression had a favourable prognostic value in terms of OS $(\mathrm{HR}=0.56,95 \% \mathrm{CI}$ : $0.33-0.94, P=0.028$ and HR $=0.50,95 \%$ CI: $0.29-0.86, P=0.011$, respectively) (Figure $2 \mathrm{~A} 3$ and A4). Among 134 HER3-positive patients 23 deaths were recorded, whereas among 133 HER3 negative patients 37 deaths were observed (log-rank $P=0.026$ ). Similarly, among 130 HER4-positive patients 21 deaths were observed vs 38 deaths among 130 HER4-negative patients (logrank $P=0.010)$. In multivariate analysis that included 260 patients, EGFR, HER2, HER3, and the number of involved axillary lymph nodes, all independently affected OS (Table 3).

With respect to DFS, elevated HER2 mRNA expression was associated with shorter DFS (52 out of 134 relapses in HER2positive $v s 35$ out of 134 relapses in HER2-negative cases, log-rank $P=0.026$ ) (Figure 2B2). The corresponding HR for relapse in HER2-positive patients was 1.62 (95\% CI: $1.06-2.49, P=0.027$ ). HER4 mRNA expression was associated with lower risk for relapse $(\mathrm{HR}=0.49,95 \% \mathrm{CI}: 0.31-0.76, P=0.002)$. Among 130 HER4positive patients 30 relapses were recorded, whereas 54 relapses were observed in 130 HER4-negative cases (log-rank $P=0.001$ ) (Figure 2B4). In multivariate analysis $(N=260)$, HER4 and the number of involved axillary nodes retained their prognostic significance for DFS (Table 3).

\section{Prognostic value of HER family members co-expression}

Regarding the prognostic significance of specific co-expression patterns of all four HER family receptors, we found that the combination of low EGFR, low HER2, high HER3, and high HER4 mRNA expression was associated with significantly longer OS compared not only with the combination of high EGFR, high HER2, low HER3, and low HER4 mRNA expression $(P<0.001)$, but also compared with all other possible co-expression profiles $(P=0.050)$. Similar findings were demonstrated for DFS ( $P=0.0021$ and $P=0.031$, respectively).

Patients with both EGFR and HER2 elevated expression had significantly worse OS compared with those with either EGFR or HER2 increased mRNA expression $(P=0.031)$, but DFS was not significantly worse $(P=0.164)$.

\section{Predictive value of HER family mRNA expression}

The interaction between mRNA expression of HER2 and the addition of paclitaxel was not significant for OS $(P=0.778)$. The HR for death in paclitaxel containing chemotherapy (E-T-CMF) among HER2-positive patients was 1.12 (95\% CI: 0.60-2.11). With respect to the DFS, the interaction was also non-significant $(P=0.976)$. Among HER2-positive cases the HR for recurrence of the paclitaxel containing treatment (E-T-CMF) was $1.05(95 \%$ CI: $0.61-1.81$ ) (Figure 3 ). In the subgroup of ER-positive patients, the interaction of HER2 mRNA expression and paclitaxel was still non-significant $(P=0.952$ and $P=0.860$ for $O S$ and DFS, respectively). Similarly, the interaction of HER2 mRNA expression and paclitaxel was not found to be significant in the subgroup of ER-negative patients $(P=0.408$ for OS and $P=0.654$ for DFS).
In addition, mRNA expression of EGFR, HER3 and HER4 was not predictive for benefit from adjuvant treatment with paclitaxel, neither for OS nor for DFS (data not shown).

\section{DISCUSSION}

In this study, we used kinetic RT-PCR to analyse the transcriptional profiling of the HER family receptor genes, in a comparatively large series of high-risk (predominantly T2-3, node-positive) early breast cancer patients, with a considerably long follow-up of 8 years. Our analysis included gene transcription assessment of all four HER family members. The majority of the clinicopathological studies have focused on protein expression and/or gene amplification of individual HER family receptors. Consequently, the clinical outcome of breast cancer patients with regard to HER family expression as a whole panel remains largely unidentified. In addition, only a small number of trials have evaluated HER family receptors at the mRNA level.

In our patient cohort, the overall concordance between kRT-PCR and IHC/FISH for the determination of HER2 status was good (74\%). Our data confirm previous studies demonstrating a substantial agreement between the results of HER2 status evaluation at the mRNA and protein levels (Ginestier et al, 2004; Gjerdrum et al, 2004; Vinatzer et al, 2005). A recent study that compared four different methods of assessment of HER2 status found a good correlation between RT-PCR and IHC, with an overall concordance that varied from 82 to $93 \%$ (Ginestier et al, 2004). In another study that assessed HER2 status at the DNA, mRNA and protein levels, the concordance of the RT-PCR with the HercepTest was $86.4 \%$ (Vinatzer et al, 2005). Using the 75 th percentile as a threshold in our exploratory analysis, the concordance between the two methods was higher (87\%). However, the prognostic ability of HER2 mRNA expression was lost, suggesting that the increase in the cutoff point is likely to miss the effect of lower, but potentially biologically important mRNA levels of HER2. With the use of the median value as a threshold and considering the IHC/FISH as the standard technique for HER2 assessment, the kRT - PCR assay was associated with a high level of sensitivity (92\%) and satisfactory specificity (67\%). The majority of HER2-positive tumours by IHC/FISH were also categorised as HER2 positive by kRT-PCR (92\%). However, among cases showing strong protein expression in IHC, $8 \%$ displayed low mRNA expression. This observation may be related either to increased mRNA degradation in FFPE tumour blocks or to accumulation of the protein product, due to aberrant catabolism. Our findings suggest that kRT-PCR is an alternative method for evaluating HER family receptors in FFPE breast tumours. However, routine methods of histological fixation and tissue processing could potentially damage or destroy RNA. In addition, dilution of tumour genomic material by nucleic acids from nonneoplastic tissue components is also a potential source of imprecision (Gjerdrum et al, 2004). Furthermore, the required equipment for kRT-PCR is not available in all histopathology laboratories and is quite expensive.

The mRNA expression levels of HER3 and HER4 receptors were positively correlated to each other and negatively correlated to EGFR, in complete agreement with previously reported data (Knowlden et al, 1998; Pawlowski et al, 2000; Bieche et al, 2003). In addition, we demonstrated a positive association between HER2 and HER3 mRNA expression. A similar correlation was described earlier, both at the mRNA and protein level (Bieche et al, 2003; Witton et al, 2003; Sassen et al, 2008). It has been suggested that the HER2/HER3 heterodimer constitutes the most mitogenic dimer in the HER family (Citri et al, 2003). HER2 does not bind to phosphatidylinositol 3-kinase (PI3K) and this function is directly mediated through the HER3 receptor (Prigent and Gullick, 1994). With respect to the relationships with the clinicopathological 

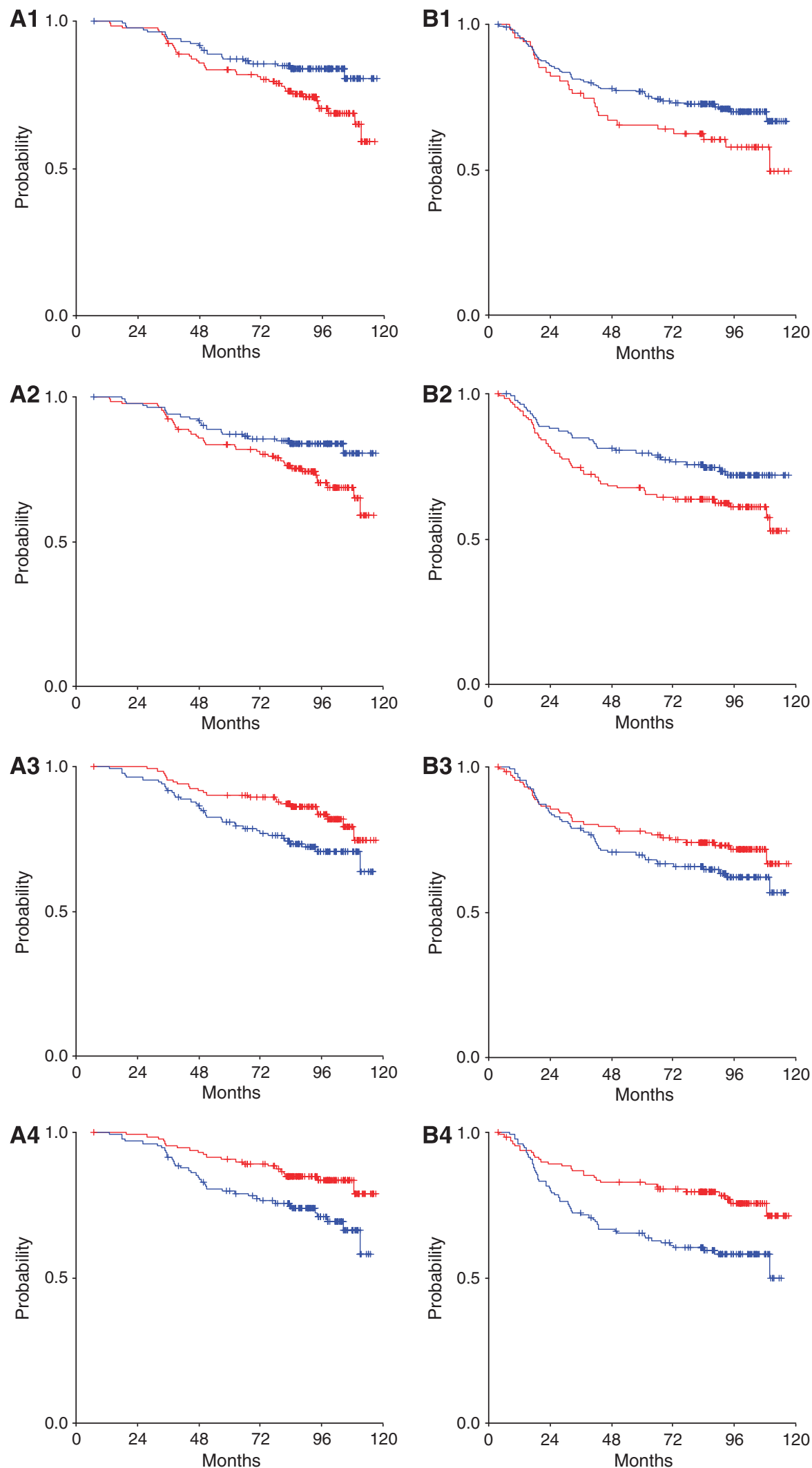

Figure $2(\mathbf{A I})$ OS $(P=0.022)$ and $\mathbf{B I}$. DFS $(P=0.076)$ for patients with EGFR mRNA expression $<75$ th percentile $(N=200$, blue line $)$ and $\geqslant 75$ th percentile $(N=67$, red line). (A2) OS $(P=0.024)$ and B2. DFS $(P=0.026)$ for patients with HER2 mRNA expression $<$ median $(N=134$, blue line $)$ and $\geqslant$ median $(N=134$, red line). (A3) OS $(P=0.026)$ and B3. DFS $(P=0.135)$ for patients with HER3 mRNA expression $<$ median $(N=133$, blue line) and $\geqslant$ median $(N=134$, red line). (A4) OS $(P=0.010)$ and B4. DFS $(P=0.00 \mathrm{I})$ for patients with HER4 mRNA expression <median $(N=130$, blue line) and $\geqslant$ median $(N=130$, red line). 
Table 3 Multivariate analysis $(N=260)$

\begin{tabular}{|c|c|c|c|c|c|c|}
\hline & \multicolumn{3}{|c|}{ os } & \multicolumn{3}{|c|}{ DFS } \\
\hline & HR & $95 \% \mathrm{Cl}$ & $P$-value & HR & $95 \% \mathrm{Cl}$ & $P$-value \\
\hline \multicolumn{7}{|l|}{ EGFR } \\
\hline$<75$ th percentile & I & - & - & I & - & - \\
\hline$\geqslant 75$ th percentile & 1.71 & $1.00-2.93$ & 0.050 & 1.52 & $0.95-2.44$ & 0.079 \\
\hline \multicolumn{7}{|l|}{ HER2 } \\
\hline$<$ Median & I & - & - & & & \\
\hline$\geqslant$ Median & 1.84 & $1.07-3.17$ & 0.027 & & & \\
\hline \multicolumn{7}{|l|}{ HER3 } \\
\hline <Median & I & - & - & & & \\
\hline$\geqslant$ Median & 0.53 & $0.30-0.91$ & 0.021 & & & \\
\hline \multicolumn{7}{|l|}{ HER4 } \\
\hline$<$ Median & & & & । & 一 & 一 \\
\hline$\geqslant$ Median & & & & 0.58 & $0.36-0.93$ & 0.022 \\
\hline \multicolumn{7}{|l|}{ Number of nodes } \\
\hline $0-3$ & । & - & - & । & - & - \\
\hline$\geqslant 4$ & 2.42 & $1.08-5.34$ & 0.032 & 2.70 & $1.38-5.28$ & 0.004 \\
\hline \multicolumn{7}{|l|}{ Grade } \\
\hline $\mid-\|$ & & & & 1 & - & - \\
\hline III-Undifferentiated & & & & 1.52 & $0.96-2.41$ & 0.071 \\
\hline \multicolumn{7}{|c|}{ Adjuvant hormonotherapy } \\
\hline No & I & - & - & । & - & - \\
\hline Yes & 0.48 & $0.23-0.99$ & 0.50 & 0.52 & $0.27-0.99$ & 0.046 \\
\hline \multicolumn{7}{|l|}{ Group of randomisation } \\
\hline E-T-CMF & 1 & - & - & 1 & - & - \\
\hline E-CMF & 0.85 & $0.51-1.4 \mid$ & 0.526 & 0.93 & $0.60-1.45$ & 0.928 \\
\hline
\end{tabular}

parameters, our findings are in accordance with previous studies evaluating the expression of HER family members in breast cancer, either at the mRNA or the protein level.

In the prognostic analyses, we found a shorter OS in patients with increased EGFR mRNA expression, using the 75th percentile as a cutoff point. In addition, the prognostic significance of EGFR for OS was maintained in the multivariate analysis. EGFR is generally considered to be a negative prognostic factor in breast cancer (Pawlowski et al, 2000; Tsutsui et al, 2002; Witton et al, 2003; Tzaida et al, 2007), but up to now, no definitive association between EGFR expression and survival has been demonstrated. The role of EGFR in HER2-mediated cellular transformation is not fully elucidated. Experiments have provided some evidence for a synergistic interaction of these receptors in cellular transformation and induction of mammary tumours (DiGiovanna et al, 1998). Moreover, interactions between EGFR and HER2 with respect to the prognosis of breast cancer patients have been reported (DiGiovanna et al, 2005). Similarly, in our study, patients with both EGFR and HER2 mRNA overexpression had significantly worse OS when compared to those with either EGFR or HER2 overexpression.

With regard to HER2, we confirmed its negative prognostic significance in terms of OS and DFS. Moreover, HER2 retained its prognostic value for OS in the multivariate analysis. Previous studies investigating the prognostic value of HER2 using real-time RT - PCR showed that this technique is clinically as useful in the assessment of HER2 status as the current standard methods, yielding comparable prognostic information (Vinatzer et al, 2005). A recent study (Bergqvist et al, 2007) used quantitative real-time PCR (Q-PCR) and RNA expression profiles (RNA-EP) to evaluate HER2 status in relation to clinical outcome in breast cancer patients. Analyses of relapse-free survival and OS on the basis of 5 and 10 years follow-up indicated that, in contrast to IHC/ chromogenic in situ hybridisation, both Q-PCR and RNA-EP analyses yielded significant results after 10 years of follow-up. These findings suggest that both Q-PCR and RNA-EP are of similar, or even superior, prognostic value compared with the current standard techniques.

The prognostic value of HER3 remains up to now unclear and the available data are contradictory. A number of studies evaluating HER family receptors have indicated a negative prognostic value of HER3 in breast cancer patients (Bieche et al, 2003; Witton et al, 2003; Sassen et al, 2008). In contrast, our present study showed a positive association between HER3 mRNA expression and OS. Moreover, in the multivariate analysis HER3 maintained its prognostic value for OS. Other studies support the positive prognostic ability of HER3 as well (Quinn et al, 1994; Pawlowski et al, 2000; Lee et al, 2007). It has also been shown that a naturally occurring secreted form of the human HER3 receptor is a potent negative regulator of neuregulin-stimulated HER family receptor activation (Lee et al, 2001).

Regarding the prognostic significance of HER4, a positive association of HER4 mRNA expression with both OS and DFS was shown. Furthermore, HER4 retained its prognostic power for DFS in the multivariate analysis. Other studies have also supported the favourable prognostic role of HER4 in breast cancer both at the mRNA and the protein level (Pawlowski et al, 2000; Suo et al, 2002; Witton et al, 2003). This positive effect is most likely associated with an inhibitory effect on growth and differentiation signalling. In cell line experiments, when HER2-positive cancer cells were transfected to overexpress HER4, a reduction in proliferation and an increase in apoptosis was observed (Sartor et al, 2001). More recent studies have further increased our knowledge regarding HER4-associated apoptosis (Naresh et al, 2006).

With respect to the prognostic power of the combined expression profile of all four HER family receptors, we found that the combination of low EGFR, low HER2, high HER3, and high HER4 mRNA expression was associated with a significantly longer OS and DFS, compared to any other combination. This finding suggests that it is the co-expression pattern, rather than the expression of individual family members, that should be taken into account when evaluating the prognosis of the patients and making individualised therapeutic decisions. Moreover, it has been demonstrated that binding of specific ligands to the extracellular domain allows for receptor homo- or heterodimerisation resulting in activation of the cytoplasmatic catalytic function, which leads to receptor autophosphorylation. This autophosphorylation triggers a complex series of signal transduction pathways, such as phosphatidylinositol 3-kinase-Akt, Ras-Raf-MEK-mitogenactivated protein kinase-dependent pathway, PLC-PKC, and JAK/STAT. These pathways affect essential tumorigenic processes, such as proliferation, differentiation, migration, inhibition of apoptosis, and enhanced survival. Therefore, apart from the co-expression of the receptors, the expression of ligands, as well as the cross-talk on different levels among the signal transduction pathways, might also be important.

In this study, we also investigated the predictive ability of the gene transcription of the HER family receptors in tumours of highrisk breast cancer patients. The patients had participated in the randomised HE10/97 trial evaluating the effect of anthracyclinebased dose-dense sequential adjuvant chemotherapy, with or without paclitaxel (Fountzilas et al, 2005). Moreover, long-term follow-up was available. Patient characteristics were well balanced between the two arms with the exception of grade, a difference also observed in the prospective clinical trial (Fountzilas et al, 2005). The unbalance concerning histological grade is an important issue, as it may have an impact on the results. However, since a multivariate analysis was performed, including both grade and 

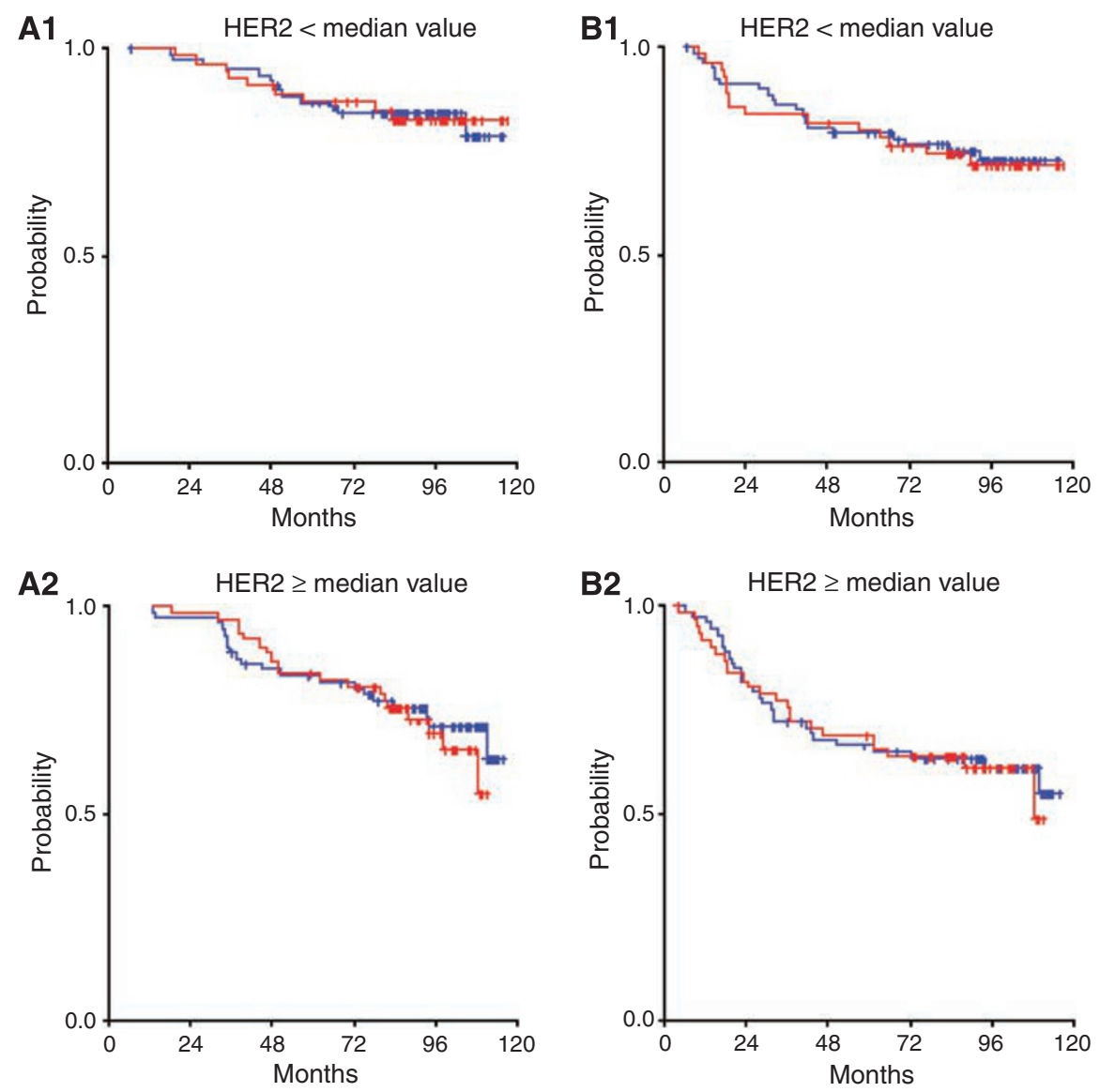

Figure 3 OS (AI and A2) and DFS (BI and B2) for patients treated with (red line) or without (blue line) paclitaxel, according to HER2 mRNA expression. Al and B I (HER2 <median): 55 (4I\%) E-T-CMF and 79 (59\%) E-CMF-treated patients. A2 and B2 (HER2 $\geqslant$ median): 62 (46\%) E-T-CMF and 72 (54\%) E-CMF-treated patients.

randomisation arm, all presented results take into account this unbalance.

To the best of our knowledge, this is the first study evaluating the effect of a taxane-containing regimen $v s$ a non-taxane treatment, according to HER2 status at the mRNA level. In the HE10/97 clinical trial, the addition of paclitaxel had no influence in DFS and OS. In our patient cohort, the interaction between HER2 mRNA expression in the tumours and the addition of paclitaxel was not significant. In the entire HE10/97 trial, the hazard of death was significantly reduced when patients with negative hormonal receptor status were treated with paclitaxel. There is evidence that ER positivity may represent a negative predictive factor for the response to chemotherapy in breast cancer (Berry et al, 2006). In our patient cohort, performing an exploratory analysis based on ER status, no significant HER2/paclitaxel interaction was found in either ER-positive or ER-negative patients. Therefore, no predictive ability of HER 2 mRNA expression for paclitaxel was established in our study.

Recently, investigators from the CALGB 9344 randomised adjuvant trial (Henderson et al, 2003) reported that patients with HER2-positive tumours derived significant benefit from the addition of paclitaxel to a doxorubicin-cyclophosphamide regimen regardless of ER status, whereas there was no additional benefit in HER2-negative, ER-positive cases (Hayes et al, 2007). In another randomised study comparing docetaxel-based (TAC) with non-docetaxel-containing adjuvant chemotherapy, the observed reduction in the risk for relapse in patients treated with TAC, did not seem to be driven by HER2 status (Martin et al, 2005). A recent study, investigating the predictive power of HER2 protein overexpression assessed by IHC in patients who were part of the HE10/97 trial, did not find predictive ability of HER2 for treatment with paclitaxel (Kostopoulos et al, 2006). However, a meta-analysis (Dhesy-Thind et al, 2008) including the above three trials (Martin et al, 2005; Kostopoulos et al, 2006; Hayes et al, 2007) demonstrated a significant interaction in terms of DFS. Patients with HER2-positive tumours derived greater benefit from the taxane, but there was a significant benefit for both groups. Up to date, clinical results regarding the interaction of HER2 receptor status and the sensitivity to taxanes are contradictory. Furthermore, preclinical data suggest that HER2 overexpression may contribute to paclitaxel resistance in breast cancer cells ( $\mathrm{Yu}$ et al, 1996; Ueno et al, 1997). Consequently, cautious interpretation of the available data is required and additional studies are warranted to clarify these relationships.

Regarding EGFR, a recently published study reported that EGFR protein expression, assessed by IHC, was a negative prognostic marker in the absence of paclitaxel in patients with high-risk operable breast cancer (Tzaida et al, 2007). In our study, no significant interaction between EGFR mRNA level and treatment with paclitaxel was found for either OS or DFS. Furthermore, no significant interaction of HER3 and HER4 mRNA expression with the treatment group was demonstrated.

In conclusion, the present study suggests that EGFR as well as HER2 mRNA overexpression are prognostic factors of worse clinical outcome in high-risk operable breast cancer patients, whereas HER3 and HER4 mRNA overexpression are both associated with a better prognosis. The combined expression profile of the HER family receptors, and not the isolated 
expression of individual members, is likely to be more important when assessing the prognosis of the patients. Furthermore, on the basis of our findings, HER2 gene transcription does not predict greater sensitivity to paclitaxel-based adjuvant chemotherapy. In addition, kinetic RT-PCR represents a valid alternative method for detection and quantification of HER family receptor gene expression in FFPE breast tumour tissues.

\section{REFERENCES}

Bartlett J, Mallon E, Cooke T (2003) The clinical evaluation of HER-2 status: which test to use? J Pathol 199: $411-417$

Bergqvist J, Ohd JF, Smeds J, Klaar S, Isola J, Nordgren H, Elmberger GP, Hellborg H, Bjohle J, Borg AL, Skoog L, Bergh J (2007) Quantitative realtime PCR analysis and microarray-based RNA expression of HER2 in relation to outcome. Ann Oncol 18: $845-850$

Berry DA, Cirrincione C, Henderson IC, Citron ML, Budman DR, Goldstein LJ, Martino S, Perez EA, Muss HB, Norton L, Hudis C, Winer EP (2006) Estrogen-receptor status and outcomes of modern chemotherapy for patients with node-positive breast cancer. JAMA 295: $1658-1667$

Bieche I, Onody P, Tozlu S, Driouch K, Vidaud M, Lidereau R (2003) Prognostic value of ERBB family mRNA expression in breast carcinomas. Int J Cancer 106: $758-765$

Birner P, Oberhuber G, Stani J, Reithofer C, Samonigg H, Hausmaninger H, Kubista E, Kwasny W, Kandioler-Eckersberger D, Gnant M, Jakesz R, Austrian Breast \& Colorectal Cancer Study Group (2001) Evaluation of the United States Food and Drug Administration-approved scoring and test system of HER-2 protein expression in breast cancer. Clin Cancer Res 7: $1669-1675$

Citri A, Skaria KB, Yarden Y (2003) The deaf and the dumb: the biology of ErbB-2 and ErbB-3. Exp Cell Res 284: 54-65

Dhesy-Thind B, Pritchard KI, Messersmith H, O'Malley F, Elavathil L, Trudeau M (2008) Her-2/neu in systemic therapy for women with breast cancer: a systemic review. Breast Cancer Res Treat 109: 209-229, e-pub ahead of print 17 July 2007

DiGiovanna MP, Lerman MA, Coffey RJ, Muller WJ, Cardiff RD, Stern DF (1998) Active signaling by $\mathrm{Neu}$ in transgenic mice. Oncogene 17: $1877-1884$

DiGiovanna MP, Stern DF, Edgerton SM, Whalen SG, Moore II D, Thor AD (2005) Relationship of epidermal growth factor receptor expression to ErbB-2 signaling activity and prognosis in breast cancer patients. J Clin Oncol 23: $1152-1160$

Dressler LG, Berry DA, Broadwater G, Cowan D, Cox K, Griffin S, Miller A, Tse J, Novotny D, Persons DL, Barcos M, Henderson IC, Liu ET, Thor A, Budman D, Muss H, Norton L, Hayes DF (2005) Comparison of HER2 status by fluorescence in situ hybridisation and immunohistochemistry to predict benefit from dose escalation of adjuvant doxorubicin-based therapy in node-positive breast cancer patients. J Clin Oncol 23: $4287-4297$

Early Breast Cancer Trialists' Collaborative Group (EBCTCG) (2005) Effects of chemotherapy and hormonal therapy for early breast cancer on recurrence and 15-year survival: an overview of the randomised trials. Lancet 365: $1687-1717$

Ellis IO, Dowsett M, Bartlett J, Walker R, Cooke T, Gullick W, Gusterson B, Mallon E, Lee PB (2000) Recommendations for HER2 testing in the UK. J Clin Pathol 53: $890-892$

Ferrero JM, Ramaioli A, Largillier R, Formento JL, Francoual M, Ettore F, Namer M, Milano G (2001) Epidermal growth factor receptor expression in 780 breast cancer patients: a reappraisal of the prognostic value based on an eight-year median follow-up. Ann Oncol 12: $841-846$

Fountzilas G, Skarlos D, Dafni U, Gogas H, Briasoulis E, Pectasides D, Papadimitriou C, Markopoulos C, Polychronis A, Kalofonos HP, Siafaka V, Kosmidis P, Timotheadou E, Tsavdaridis D, Bafaloukos D, Papakostas P, Razis E, Makrantonakis P, Aravantinos G, Christodoulou C, Dimopoulos AM (2005) Postoperative dose-dense sequential chemotherapy with epirubicin, followed by CMF with or without paclitaxel, in patients with high-risk operable breast cancer: a randomized phase III study conducted by the Hellenic Cooperative Oncology Group. Ann Oncol 16: $1762-1771$

Gennari A, Sormani MP, Pronzato P, Puntoni M, Colozza M, Pfeffer U, Bruzzi P (2008) HER2 status and efficacy of adjuvant anthracyclines in

\section{ACKNOWLEDGEMENTS}

We thank Ms Georgia Vourli (MSc) for the statistical analysis, Ms Evita Fragou and Ms Dimitra Katsala for monitoring the study, Ms Maria Moschoni for coordinating the data management, Ms Thalia Spinari for tissue sample collection, and Ms Inke Feder and $\mathrm{Mr}$ Patrick Maass for excellent technical assistance. early breast cancer: a pooled analysis of randomized trials. J Natl Cancer Inst 100: $14-20$

Ginestier C, Charafe-Jauffret E, Penault-Llorca F, Geneix J, Adélaïde J, Chaffanet M, Mozziconacci MJ, Hassoun J, Viens P, Birnbaum D, Jacquemier J (2004) Comparative multi-methodological measurement of ERBB2 status in breast cancer. J Pathol 202: 286-298

Gjerdrum LM, Sorensen BS, Kjeldsen E, Sorensen FB, Nexo E, HamiltonDutoit S (2004) Real-time quantitative PCR of microdissected paraffinembedded breast carcinoma: an alternative method for HER-2/neu analysis. J Mol Diagn 6: 42-51

Gonzalez-Angulo AM, Krishnamurthy S, Yamamura Y, Broglio KR, Pusztai L, Buzdar AU, Hortobagyi GN, Esteva FJ (2004) Lack of association between amplification of her-2 and response to preoperative taxanes in patients with breast carcinoma. Cancer 101: 258-263

Gusterson BA, Gelber RD, Goldhirsch A, Price KN, Säve-Söderborgh J, Anbazhagan R, Styles J, Rudenstam CM, Golouh R, Reed R (1992) Prognostic importance of c-erbB-2 expression in breast cancer. J Clin Oncol 10: $1049-1056$

Hayes DF, Thor AD, Dressler LG, Weaver D, Edgerton S, Cowan D, Broadwater G, Goldstein LJ, Martino S, Ingle JN, Henderson IC, Norton L, Winer EP, Hudis CA, Ellis MJ, Berry DA, Cancer and Leukemia Group B (CALGB) Investigators (2007) HER2 and response to paclitaxel in node-positive breast cancer. $N$ Engl J Med 357: 1496-1506

Henderson IC, Berry DA, Demetri GD, Cirrincione CT, Goldstein LJ, Martino S, Ingle JN, Cooper MR, Hayes DF, Tkaczuk KH, Fleming G, Holland JF, Duggan DB, Carpenter JT, Frei III E, Schilsky RL, Wood WC, Muss HB, Norton L (2003) Improved outcomes from adding sequential paclitaxel but not from escalating doxorubicin dose in an adjuvant chemotherapy regimen for patients with node-positive primary breast cancer. J Clin Oncol 21: 976-983

Hudis CA, Barlow WE, Costantino JP, Gray RJ, Pritchard KI, Chapman JA, Sparano JA, Hunsberger S, Enos RA, Gelber RD, Zujewski JA (2007) Proposal for standardized definitions for efficacy end points in adjuvant breast cancer trials: the STEEP system. J Clin Oncol 25: 2127-2132

Klijn JG, Berns PM, Schmitz PI, Foekens JA (1992) The clinical significance of epidermal growth factor receptor (EGF-R) in human breast cancer: a review on 5232 patients. Endocr Rev 13: 3-17

Knowlden JM, Gee JM, Seery LT, Farrow L, Gullick WJ, Ellis IO, Blamey RW, Robertson JF, Nicholson RI (1998) c-erbB-3 and c-erbB-4 expression is a feature of the endocrine responsive phenotype in clinical breast cancer. Oncogene 17: 1949-1957

Konecny GE, Thomssen C, Luck HJ, Untch M, Wang HJ, Kuhn W, Eidtmann H, du Bois A, Olbricht S, Steinfeld D, Möbus V, von Minckwitz G, Dandekar S, Ramos L, Pauletti G, Pegram MD, Jänicke F, Slamon DJ (2004) Her-2/neu gene amplification and response to paclitaxel in patients with metastatic breast cancer. J Natl Cancer Inst 96: 1141-1151

Kostopoulos I, Arapantoni-Dadioti P, Gogas H, Papadopoulos S, MalamouMitsi V, Scopa CD, Markaki S, Karagianni E, Kyriakou V, Margariti A, Kyrkou E, Pavlakis K, Zaramboukas T, Skordalaki A, Bourli A, Markopoulos C, Pectasides D, Dimopoulos MA, Skarlos D, Fountzilas G (2006) Evaluation of the prognostic value of HER-2 and VEGF in breast cancer patients participating in a randomized study with dose-dense sequential adjuvant chemotherapy. Breast Cancer Res Treat 96: 251-261

Lee H, Akita RW, Sliwkowski MX, Maihle NJ (2001) A naturally occurring secreted human ErbB3 receptor isoform inhibits heregulin-stimulated activation of ErbB2, ErbB3, and ErbB4. Cancer Res 61: 4467-4473

Lee Y, Cho S, Seo JH, Shin BK, Kim HK, Kim I, Kim A (2007) Correlated expression of erbB-3 with hormone receptor expression and favorable clinical outcome in invasive ductal carcinomas of the breast. Am J Clin Pathol 128: 1041 - 1049

Martin M, Pienkowski T, Mackey J, Pawlicki M, Guastalla JP, Weaver C, Tomiak E, Al-Tweigeri T, Chap L, Juhos E, Guevin R, Howell A, 
Fornander T, Hainsworth J, Coleman R, Vinholes J, Modiano M, Pinter T, Tang SC, Colwell B, Prady C, Provencher L, Walde D, RodriguezLescure A, Hugh J, Loret C, Rupin M, Blitz S, Jacobs P, Murawsky M, Riva A, Vogel C, Breast Cancer International Research Group 001 Investigators (2005) Adjuvant docetaxel for node-positive breast cancer. $N$ Engl J Med 352: $2302-2313$

Mass R, Sanders C, Charlene K, Johnson L, Everett T, Anderson S (2000) The concordance between the Clinical Trials Assay (CTA) and fluorescence in situ hybridization (FISH) in the Herceptin Pivotal Trials [abstract]. Proc Am Soc Clin Oncol 19: 291

McShane LM, Altman DG, Sauerbrei W, Taube SE, Gion M, Clark GM, Statistics Subcommittee of the NCI-EORTC Working Group on Cancer Diagnostics (2005) Reporting recommendations for tumor marker prognostic studies. J Clin Oncol 23: 9067-9072

Mosesson Y, Yarden Y (2004) Oncogenic growth factor receptors: implications for signal transduction therapy. Semin Cancer Biol 14: $262-270$

Naresh A, Long W, Vidal GA, Wimley WC, Marrero L, Sartor CI, Tovey S, Cooke TG, Bartlett JM, Jones FE (2006) The ERBB4/HER4 intracellular domain $4 \mathrm{ICD}$ is a $\mathrm{BH} 3$-only protein promoting apoptosis of breast cancer cells. Cancer Res 66: 6412-6420

Pawlowski V, Revillion F, Hebbar M, Hornez L, Peyrat JP (2000) Prognostic value of the type I growth factor receptors in a large series of human primary breast cancers quantified with a real-time reverse transcriptionpolymerase chain reaction assay. Clin Cancer Res 6: 4217-4225

Prigent SA, Gullick WJ (1994) Identification of c-erbB-3 binding sites for phosphatidylinositol $3^{\prime}$-kinase and SHC using an EGF receptor/c-erbB-3 chimera. EMBO J 13: $2831-2841$

Pritchard KI, Messersmith H, Elavathil L, Trudeau M, O’Malley F, DhesyThind B (2008) HER-2 and topoisomerase II as predictors of response to chemotherapy. J Clin Oncol 26: 736-744

Quinn CM, Ostrowski JL, Lane SA, Loney DP, Teasdale J, Benson FA (1994) C-erbB-3 protein expression in human breast cancer: comparison with other tumour variables and survival. Histopathology 25: 247-252

Rampaul RS, Pinder SE, Wencyk PM, Nicholson RI, Blamey RW, Robertson JF, Ellis IO (2004) Epidermal growth factor receptor status in operable invasive breast cancer: is it of any prognostic value? Clin Cancer Res 10: 2578

Sartor CI, Zhou H, Kozlowska E, Guttridge K, Kawata E, Caskey L, Harrelson J, Hynes N, Ethier S, Calvo B, Earp III HS (2001) Her4 mediates ligand-dependent antiproliferative and differentiation responses in human breast cancer cells. Mol Cell Biol 21: 4265-4275
Sassen A, Rochon J, Wild P, Hartmann A, Hofstaedter F, Schwarz S, Brockhoff G (2008) Cytogenetic analysis of HER1/EGFR, HER2, HER3, AND HER4 in 278 breast cancer patients. Breast Cancer Res Treat 10: R2; e-pub ahead of print

Slamon DJ, Clark GM, Wong SG, Levin WJ, Ullrich A, McGuire WL (1987) Human breast cancer: correlation of relapse and survival with amplification of the HER-2/neu oncogene. Science 235: 177-182

Suo Z, Risberg B, Karlsson MG, Willman K, Tierens A, Skovlund E, Nesland JM (2002) EGFR family expression in breast carcinomas. C-erbB-2 and c-erbB-4 receptors have different effects on survival. I Pathol 196: $17-25$

Travis A, Pinder SE, Robertson JF, Bell JA, Wencyk P, Gullick WJ, Nicholson RI, Poller DN, Blamey RW, Elston CW, Ellis IO (1996) C-erbB3 in human breast carcinoma: expression and relation to prognosis and established prognostic indicators. Br J Cancer 74: 229-233

Tsutsui S, Ohno S, Murakami S, Hachitanda Y, Oda S (2002) Prognostic value of epidermal growth factor receptor (EGFR) and its relationship to the estrogen receptor status in 1029 patients with breast cancer. Breast Cancer Res Treat 71: 67-75

Tzaida O, Gogas H, Dafni U, Kyroudi A, Papaspyrou I, Kyriakou V, Malamou-Mitsi V, Alamani M, Skopa C, Kostopoulos I, Kastritis E, Pectasides D, Briasoulis E, Kalofonos HP, Aravantinos G, Fountzilas G, Arapantoni-Dadioti P (2007) Evaluation of the prognostic and predictive value of HER-1/EGFR in breast cancer patients participating in a randomized study with dose-dense sequential adjuvant chemotherapy. Oncology 72: 388-396

Ueno NT, Yu D, Hung MC (1997) Chemosensitization of HER-2/neuoverexpressing human breast cancer cells to paclitaxel (Taxol) by adenovirus type $5 \mathrm{E} 1 \mathrm{~A}$. Oncogene 15: 953-960

Vinatzer U, Dampier B, Streubel B, Pacher M, Seewald MJ, Stratowa C, Kaserer K, Schreiber M (2005) Expression of HER2 and the coamplified genes GRB7 and MLN64 in human breast cancer: quantitative real-time reverse transcription-PCR as a diagnostic alternative to immunohistochemistry and fluorescence in situ hybridization. Clin Cancer Res 11: $8348-8357$

Witton CJ, Reeves JR, Going JJ, Cooke TG, Bartlett JM (2003) Expression of the HER1-4 family of receptor tyrosine kinases in breast cancer. J Pathol 200: $290-297$

Yu D, Liu B, Tan M, Li J, Wang SS, Hung MC (1996) Overexpression of c-erbB-2/neu in breast cancer cells confers increased resistance to Taxol via mdr-1-independent mechanisms. Oncogene 13: 1359-1365 